Manuscript ID

ZUMJ-1910-1591 (R1)

DOI

10.21608/zumj.2019.18291.1591

ORIGINAL ARTICLE

\title{
Pulmonary Function Tests in children suffering from Inflammatory Bowel Diseases in Zagazig University Hospital
}

\author{
Hend Abd-Elhamid Abd-Elhafiz Abd-Elhamid (1)*, Hatem Mohamed Elsayed Hussein (1), \\ Hossam Fathi Elsaadany ${ }^{(1)}$ \\ 1: Pediatric department, Faculty of medicine, Zagazig university, Zagazig , El sharkia, Egypt
}

*Corresponding Author:

Name: Hend Abd-Elhamid Abd-

Elhafiz Abd-Elhamid.

Pediatric department, Faculty of medicine, Zagazig university, Zagazig, El sharkia, Egypt

E-mail:

hendabdelhameed05@gmail.com

Submit Date

16-10-2019

Revise Date

09-11-2019

Accept Date

2019-11-13

\section{Background: Extra intestinatraCT} disease (IBD) are a systemic illness that may affect up to half of all patients. Among the extra intestinal manifestations of IBD, those involving respiratory system are relatively rare. However, there is a wide variation of such manifestations, spanning from airway disease to lung parenchymal disease, pleural disease, enteric pulmonary fistulas and pulmonary function test abnormalities. This study aimed to detect the abnormalities of pulmonary function tests in inflammatory bowel diseases in children Method: A prospective Cross sectional study was carried out at Gastro entrology unit and pulmonary unit pediatric department, in Zagazig University hospitals during the period from December 2016 to January 2018. Twenty patients with inflammatory bowel disease were recruited in the study and full history and clinical examination was taken. full lab was drawn such as complete blood count, $\mathrm{C}$ reactive protein, erythrocyte sedimentation rate. Pulmonary function tests (PFTs) was performed with spirometer. Statistical analysis was done for these data. Results: PFT was abnormal in $40 \%$ patients. abnormal PFT was classifed into restrictive $6(30 \%)$, and obstructive defects $2(10 \%)$.IBD patients with active disease have abnormal pulmonary function tests .No relation of PFT abnormalities was found with age, sex, duration of disease, serum albumin, and hemoglobin levels, and other extraintestinal manifestation (arthritis/arthralgia) and drugs used to treat IBD. Conclusion: the study proved that IBD patients with active disease have abnormal pulmonary functions with predominant involvement of restrictive. Active IBD was more often associated with abnormal PFT than the disease in remission.

Keywords: inflammatory bowel disease, extra intestinal manifestation and abnormal PFT

\section{INTRODUCTION}

I nflammatory bowel diseases (IBDs) are chronic gastrointestinal tract diseases of unknown etiology [1] .IBD presenting with diarrhea that almost always contains blood, fatigue, anemia, and weight loss. The onset of symptoms may be insidious, with diarrhea that is initially non-bloody, and poor weight gain. Some children have a more fulminant presentation, with severe abdominal pain, frankly bloody diarrhea, tenesmus, fever, leukocytosis, and hypoalbuminemia ${ }^{[2]}$.More than one-third of the IBD patients are affected by extraintestinal manifestations .Pulmonary manifestations have been reported in IBD patients, such as inflammatory tracheal stenosis, bronchiolitis obliterans organizing pneumonia, panbronchiolitis, interstitial pneumonitis, and apical fibrosis ${ }^{[4]}$. The relationship between pulmonary impairment and activity of disease also has not been clearly established in IBD patients. 
Some authors report that pulmonary function test (PFT) abnormalities in the patients of IBD are associated with the activity of disease. $^{[1]}$ This study aimed to detect the abnormalities of pulmonary function tests in inflammatory bowel diseases in children.

\section{METHODS}

A prospective Cross sectional study was carried out at Gastro entrology unit and pulmonary unit pediatric department, Zagazig University hospitals during the period from December 2016 to January 2018 . Twenty patients with inflammatory bowel disease) were enrolled for this study, all were used to extract demographic and outcome data. We used these data for analysis, we measured pulmonary function test for all children at the day of admission. 16 children were diagnosed as ulcerative colitis, 4 children were diagnosed as crohn disease .

The study was approved by the research ethical committee of Faculty of Medicine, Zagazig University. The work has been carried out in accordance with The Code of Ethics of the World Medical Association (Declaration of Helsinki) for studies involving humans

Patient: Inclusion criteria: were Children diagnosed as inflammatory bowel diseases By endoscopy and Histopathology were involved in our study from both sexes with age range from4-18y, Exclusion criteria: were Patients with chronic GIT problems other than IBD, with any neurologic, cardiac, upper airway troubles interfering with PFT technique, with Chronic lung diseases were excluded from this study.

Methods: Each Patient is subjected to complete history taking including personal, present history taking (duration of diseases and type of drug with doses). past history of disease, drug, operation and recurrence, Diseases activity index. Complete examination for patients which is done for assessment of body systems including general examination for vital signs, measurement, .Also Chest examination, Abdomen examination were done.

Investigation : routine laboratory investigation as CBC, CRP, ESR, Stool analysis, stool calprotectin, KFT, and LFT were done and other investigation as Chest $\mathrm{X}$ ray, Barium studies and Colonoscopy, upper endoscopy finding and PFT

Pulmonary function test: Pulmonary function tests were assessed the day after admission, during remission and relapse. Pulmonary function testing were performed with spirometer (2010 Ganshorn, Medizin Electronic $\mathrm{GmbH}$ Industries, Trasse 6-8, 97618, Nieder Lauer, Germany. Software version LF 8.5) to measure the predicted forced vital capacity (FVC), the predicted forced expiratory volume in 1 s (FEV1), and their ratio (FEV1/FVC) Normal physiology was defined by all measurements being $>80 \%$ predicted, a restrictive defect as a reduced ( $<80 \%$ predicted) FVC with an FEV1/FVC ratio of $>70 \%$ predicted or reduced DLCO ( $<80 \%$ predicted), and an obstructive defect as a reduced FEV1 with a normal FVC and a low FEV1/FVC ratio ( $<70 \%$ predicted). Small airway disease was defined as reduced FEV1 ( $<70 \%$ predicted), low FEV1/ FVC $(<70 \%$ predicted) ratio, and reduced MEF25 $-75(<60$ predicted) ${ }^{[5]}$.

Disease activity: Patients with active disease were classified as mild, moderate, or severe as per Truelove score. This score includes stool frequency, occurrence of blood in stools, fever, hemoglobin $(\mathrm{Hb})$ levels, and erythrocyte sedimentation rate (ESR). Patients were considered in clinical remission if they had one or two stools a day without blood, no fever, or tachycardia, along with normal $\mathrm{Hb}$ determinations and ESR. ${ }^{[5]}$

Extent of disease: Extent of the disease was assessed on colonoscopy as proctitis, leftsided colitis, or pan colitis. Proctitis was defined as involvement of the rectum only, left-sided colitis as left colon up to splenic flexure and pancolitis as extensive disease beyond splenic flexure. ${ }^{[5]}$

Ethical Clearance: Written Informed consent was taken from the patient parents to participate in the study. Approval for performing the study was obtained from Pediatrics Departments, Zagazig University Hospitals after taking Institutional Review Board (IRB) approval. The work has been carried out in accordance with the code of ethics of the world medical association 
(Decleration of Helsinki) for studies involving humans.

\section{Statistical analysis}

Statistical analysis was performed using SPSS version 15 (SPSS, Inc., Chicago, IL, USA). Continuous data were expressed as median and range. Continuous and categorical variables were analyzed using Mann-Whitney U-test and chisquare test with Yates' correction as applicable, respectively. Intergroup comparison of more than two variables was performed using KruskalWallis H-test. Spearman or Pearson correlation coefficient was used to find out the relationship between the two continuous variables depending on distribution of the data.

All $P$ values were based on a 2-tailed distribution, and the corresponding $P$ value:

- Non-significant (NS) difference if $\mathrm{P}>0.05$.

- $\quad$ Significant(S) difference if $\mathrm{P}<$ 0.05 .

- Highly significant (HS) difference if $\mathrm{P}<0.00$.

\section{RESULTS}

Baseline characteristics were demonstrated in table (1). The mean age \pm SD was $9 \pm 3.7$ years, and the majority were female $(70 \%)$. Eighty percent of cases had ulcerative colitis. Mean body mass index (BMI) \pm SD was $18.3 \pm 2.4$ Pulmonary function tests of the studied (IBD) patients were abnormal (40\%), mostly restrictive $(30 \%)$ were demonstrated in table (2).
There is statistically significantly strong positive correlation existed between frequency of attack of relapse and FVC/FEV1 ratio $(P=.024)$.No statistically significant differences between other relevant study parameters and $\mathrm{FVC} / \mathrm{FEV} 1$ ratio of the studied (IBD) patients $(P>.05)$ was shown table (3).

There is Statistically significantly moderate negative correlations existed between body mass index, frequency of attack of relapse and FEV1\% $(P=.036$ and $P=.007$, respectively). However, no statistically significant differences between other relevant study parameters and FEV1\% of the studied (IBD) patients $(P>.05)$, was shown in table (4).

Patients with abnormal pulmonary functions had statistically significantly lower body mass index than patients with normal pulmonary functions $(P=.020)$.Also, there was a statistically significant association between pulmonary function and colonoscopy biopsy findings $(P=.028)$. However, no statistically significant differences between other relevant study parameters and pulmonary function of the studied (IBD) patients $(P>.05)$, was shown in table (5).

A scatter plot with a regression line of FEV1\% against body mass index of the studied (IBD) patients was shown in figure (1).

A scatter plot with a regression line of FEV1/FVC ratio against frequency of attack of relapse of the studied (IBD) patients was shown in figure (2). 
Table 1: Demographics of the studied (IBD) patients

\begin{tabular}{|c|c|}
\hline Variables & Age (years) \\
\hline mean \pm SD & $9 \pm 3.7$ \\
\hline median(range) & $8(4-15)$ \\
\hline \multicolumn{2}{|l|}{$\operatorname{Sex}, n(\%)$} \\
\hline Female & 14(70) \\
\hline Male & $6(30)$ \\
\hline \multicolumn{2}{|l|}{ Residency, $n(\%)$} \\
\hline Urban & $8(40)$ \\
\hline Rural & $12(60)$ \\
\hline \multicolumn{2}{|c|}{ Age of onset (years) } \\
\hline $\operatorname{mean} \pm \mathrm{SD}$ & $6.5 \pm 3.9$ \\
\hline median(range) & $5.8(0.5-13)$ \\
\hline \multicolumn{2}{|l|}{ Weight (kg) } \\
\hline $\operatorname{mean} \pm \mathrm{SD}$ & $24.8 \pm 9.0$ \\
\hline median(range) & $23(12-42)$ \\
\hline \multicolumn{2}{|l|}{ Height $(\mathrm{cm})$} \\
\hline mean \pm SD & $114.5 \pm 17.3$ \\
\hline median(range) & $110(80-150)$ \\
\hline \multicolumn{2}{|l|}{ BMI $\left(\mathrm{kg} / \mathrm{m}^{2}\right)$} \\
\hline mean \pm SD & $18.3 \pm 2.4$ \\
\hline median(range) & 17.8(15.4-24.1) \\
\hline
\end{tabular}

Table 2: Pulmonary function tests of the studied (IBD) patients

\begin{tabular}{|l|c|}
\hline FVariables & \\
\hline mean \pm SD & \\
\hline median(range) & $78.7 \pm 5.7$ \\
\hline FEV1\% & $80(66-87)$ \\
\hline mean \pm SD & \\
\hline median(range) & $78.2 \pm 3.1$ \\
\hline FEV1/FVC ratio & $79(70-82)$ \\
\hline mean \pm SD & \\
\hline median(range) & $1 \pm 0.05$ \\
\hline Pulmonary function, $n(\%)$ & $1(0.9-1.1)$ \\
\hline Normal & $12(60)$ \\
\hline Restrictive & $6(30)$ \\
\hline Obstructive & $2(10)$ \\
\hline
\end{tabular}

FVC, forced vital capacity; FEV1, forced expiratory volume. Total number=20 
Table 3: Relations between relevant study parameters and FEV1/FVC ratio of the studied (IBD) patients

\begin{tabular}{|c|c|c|c|c|c|}
\hline \multicolumn{4}{|l|}{ Variables } & Test & $P$-value \\
\hline \multicolumn{4}{|c|}{$\operatorname{BMI}\left(\mathbf{k g} / \mathbf{m}^{2}\right)$} & $r_{s}=.290$ & .22 \\
\hline \multicolumn{4}{|c|}{ Frequency of attack of relapse } & $r_{s}=.504$ & .024 \\
\hline \multicolumn{4}{|c|}{ Main complain } & \multirow{3}{*}{$\begin{array}{c}\text { Kruskalwallis } \mathrm{H} \\
\text { test }=1.1\end{array}$} & \multirow[t]{3}{*}{.57} \\
\hline $\begin{array}{l}\text { Abdominal pain } \\
\text { and bloody } \\
\text { diarrhea, } n=5\end{array}$ & \multicolumn{2}{|c|}{ Abdominal pain and weight loss, $n=4$} & $\begin{array}{c}* \text { Other } \\
\text { complains, } \\
n=11\end{array}$ & & \\
\hline $1(0.9-1.1)$ & \multicolumn{2}{|c|}{$1(1-1.06)$} & $1(0.94-1)$ & & \\
\hline \multicolumn{4}{|c|}{ General examination } & \multirow{3}{*}{$\begin{array}{c}\text { Mann Whitney } \\
U \text { test }=43.5\end{array}$} & \multirow[t]{3}{*}{.88} \\
\hline \multicolumn{3}{|c|}{ Weight loss, $n=13$} & *Others, $n=7$ & & \\
\hline \multicolumn{3}{|l|}{$1(0.94-1.1)$} & $1(0.9-1.10)$ & & \\
\hline \multicolumn{4}{|c|}{ Abdominal examination } & \multirow{3}{*}{$\begin{array}{c}\text { Kruskalwallis } \mathrm{H} \\
\text { test }=5.7\end{array}$} & \multirow[t]{3}{*}{.057} \\
\hline \multirow{2}{*}{\multicolumn{2}{|c|}{ Abdominal distension, $n=8$}} & $\begin{array}{l}\text { Abdominal } \\
\text { rigidity, } n=7\end{array}$ & *Others, $n=5$ & & \\
\hline & & $1(0.9-1)$ & $1(1-1.1)$ & & \\
\hline \multicolumn{3}{|c|}{ Colonoscopy biopsy } & & \multirow{3}{*}{$\begin{array}{c}\text { Kruskalwallis } \mathrm{H} \\
\text { test }=5.8\end{array}$} & \multirow[t]{3}{*}{.056} \\
\hline Crypt abscess, $n=7$ & & $\begin{array}{c}\text { Crypt abscess and } \\
\text { neutrophilic infiltrate, } \\
n=7\end{array}$ & *others, $n=6$ & & \\
\hline $1(0.96-1.1)$ & & $1(0.9-1)$ & $1(1-1.04)$ & & \\
\hline \multicolumn{3}{|c|}{ Stool calprotectin (mg/kg) } & & $r_{s}=.383$ & .095 \\
\hline
\end{tabular}

Table 4: Relations between relevant study parameters and FEV1\% of the studied (IBD) patients

\begin{tabular}{|c|c|c|c|c|c|}
\hline \multicolumn{4}{|l|}{ Variables } & Test & $P$-value \\
\hline \multicolumn{4}{|l|}{$\operatorname{BMI}\left(\mathrm{kg} / \mathrm{m}^{2}\right)$} & $r_{s}=-.471$ & .036 \\
\hline \multicolumn{4}{|c|}{ Frequency of attack of relapse } & $r_{s}=-580$ & .007 \\
\hline \multicolumn{4}{|c|}{ Main complain } & \multirow{3}{*}{$\begin{array}{c}\text { Kruskalwallis } \\
\mathrm{H} \text { test }=2.4\end{array}$} & \multirow[t]{3}{*}{.30} \\
\hline $\begin{array}{l}\text { Abdominal pain } \\
\text { and bloody } \\
\text { diarrhea, } n=5\end{array}$ & Abdon & nal pain and weight loss, & $\begin{array}{c}* \text { Other } \\
\text { complains, } \\
n=11\end{array}$ & & \\
\hline $80(79-80)$ & & $78(78-79)$ & $80(70-82)$ & & \\
\hline \multicolumn{4}{|c|}{ General examination } & \multirow{3}{*}{$\begin{array}{c}\text { Mann Whitney } \\
U \text { test }=21.5\end{array}$} & \multirow[t]{3}{*}{.056} \\
\hline \multicolumn{3}{|c|}{ Weight loss, $n=13$} & *Others, $n=7$ & & \\
\hline \multicolumn{3}{|c|}{$80(70-82)$} & $78(73-81)$ & & \\
\hline \multicolumn{4}{|c|}{ Abdominal examination } & \multirow{3}{*}{$\begin{array}{c}\text { Welch's } \\
\text { ANOVA } \\
F=0.80\end{array}$} & \multirow{3}{*}{.48} \\
\hline \multicolumn{2}{|c|}{ Abdominal distension, $n=8$} & $\begin{array}{c}\text { Abdominal } \\
\text { rigidity, } n=7\end{array}$ & *Others, $n=5$ & & \\
\hline \multicolumn{2}{|c|}{$77 \pm 4.2$} & $79 \pm 2.3$ & $79 \pm 0.71$ & & \\
\hline \multicolumn{4}{|c|}{ Colonoscopy biopsy } & \multirow{3}{*}{$\begin{array}{c}\text { Kruskalwallis } \\
\text { H test }=2.1\end{array}$} & \multirow[t]{3}{*}{.36} \\
\hline \multicolumn{2}{|c|}{ Crypt abscess, $n=7$} & $\begin{array}{c}\text { Crypt abscess and } \\
\text { neutrophilic infiltrate, } \\
n=7\end{array}$ & *others, $n=6$ & & \\
\hline \multicolumn{2}{|l|}{$79(70-80)$} & $80(78-81)$ & $77(73-82)$ & & \\
\hline \multicolumn{4}{|c|}{ Stool calprotectin $(\mathrm{mg} / \mathrm{kg})$} & $r_{s}=.158$ & .51 \\
\hline
\end{tabular}


Table 5: Relations between relevant study parameters and pulmonary function of the studied (IBD) patients

\begin{tabular}{|c|c|c|c|c|}
\hline \multirow[t]{2}{*}{ Variables } & \multicolumn{2}{|c|}{ Pulmonary function } & \multirow{2}{*}{$\begin{array}{l}\text { Test of } \\
\text { significance }\end{array}$} & \multirow[t]{2}{*}{$P$-value } \\
\hline & $\begin{array}{c}\text { Normal } \\
n=12\end{array}$ & $\begin{array}{c}\text { Abnormal } \\
n=8\end{array}$ & & \\
\hline BMI $\left(\mathrm{kg} / \mathrm{m}^{2}\right)$ & & & Mann & .020 \\
\hline median(range) & 17.3(15.4-19.2) & 19.1(17.2-24.1) & $\begin{array}{l}\text { Whitney } U \\
\text { test }=18\end{array}$ & \\
\hline $\begin{array}{l}\text { Frequency of attack of } \\
\text { relapse, } n\end{array}$ & & & $\begin{array}{l}\text { Fisher's } \\
\text { Exact Test }\end{array}$ & .07 \\
\hline No relapse, $n=8$ & $7(58)$ & $1(13)$ & & \\
\hline$\geq$ once a year, $n=12$ & $5(42)$ & $7(87)$ & & \\
\hline Main complain, $n$ & & & Fisher's & .84 \\
\hline $\begin{array}{l}\text { Abdominal pain and bloody } \\
\text { diarrhea, } n=5\end{array}$ & $3(25)$ & $2(25)$ & $\begin{array}{c}\text { Exact } \\
\text { Test }=0.62\end{array}$ & \\
\hline $\begin{array}{l}\text { Abdominal pain and weight } \\
\text { loss, } n=4\end{array}$ & $3(25)$ & $1(12)$ & & \\
\hline *Other complains, $n=11$ & $6(50)$ & $5(63)$ & & \\
\hline General examination, $n$ & & & Fisher's & .36 \\
\hline Weight loss , $n=13$ & $9(75)$ & $4(50)$ & Exact Test & \\
\hline Others, $n=7$ & $3(25)$ & $4(50)$ & & \\
\hline $\begin{array}{l}\text { Abdominal examination, } \\
n\end{array}$ & & & $\begin{array}{l}\text { Fisher's } \\
\text { Exact }\end{array}$ & .099 \\
\hline Abdominal distension, $n=8$ & $5(42)$ & $3(38)$ & Test $=4.9$ & \\
\hline Abdominal rigidity, $n=7$ & $6(50)$ & $1(12)$ & & \\
\hline *Others, $n=5$ & $1(8)$ & $4(50)$ & & \\
\hline Colonoscopy biopsy & & & Fisher's & .028 \\
\hline Crypt abscess, $n=7$ & $3(25)$ & $4(50)$ & Exact & \\
\hline $\begin{array}{l}\text { Crypt abscess and } \\
\text { neutrophilic infiltrate, } n=7\end{array}$ & $7(58)$ & $0(0)$ & & \\
\hline *others, $n=6$ & $2(17)$ & $4(50)$ & & \\
\hline Stool calprotectin (mg/kg) & & & Mann & .21 \\
\hline median(range) & $210(58-798)$ & $304(120-1318)$ & $\begin{array}{l}\text { Whitney } U \\
\text { test }=31\end{array}$ & \\
\hline
\end{tabular}




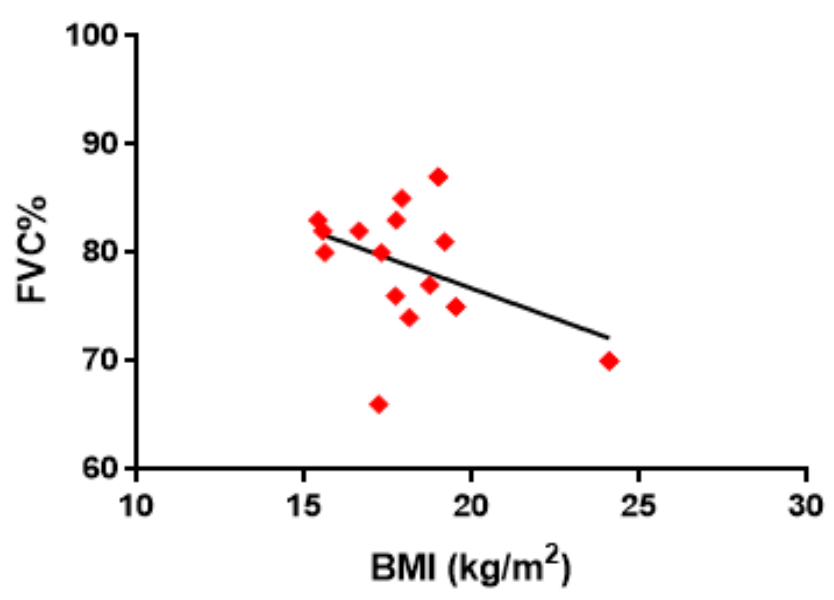

Figure 1. A scatter plot with a regression line of FVC\% against body mass index of the studied (IBD) patients

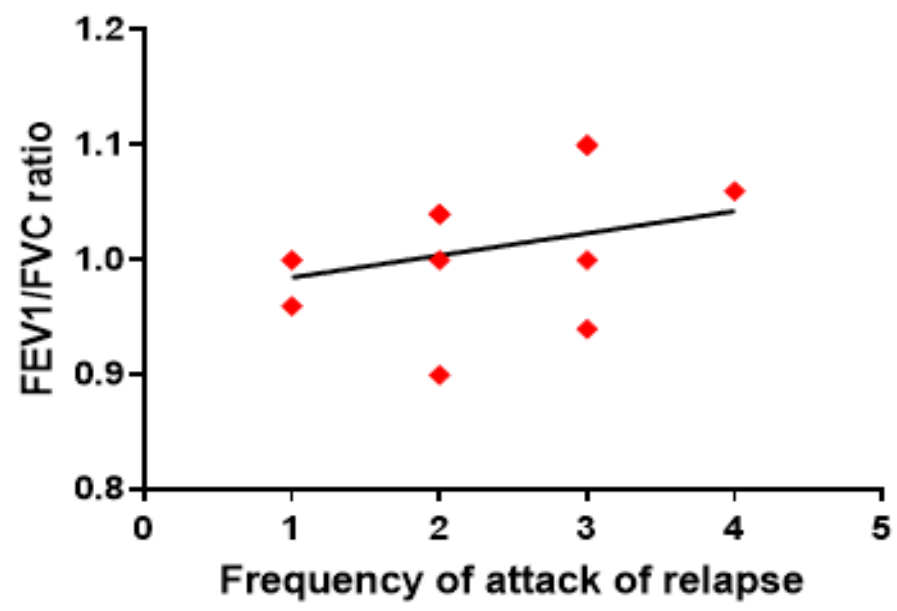

Figure 2. A scatter plot with a regression line of FEV1/FVC ratio against frequency of attack of relapse of the studied (IBD) patients

\section{DISCUSSION}

Inflammatory bowel diseases (IBDs) are chronic inflammatory diseases of unknown etiology that commonly involve the gastrointestinal tract. Crohn's disease (CD) and ulcerative colitis (UC) are the two main forms of chronic IBD. Extra intestinal and systemic manifestations occur commonly in patients with IBD (21\%-41\%), increase with duration of intestinal disease, and affect most organ systems ${ }^{[6]}$.

This study showed mean of age \pm SD was $9 \pm 3.7$ years in comparison to Peradzy_nska et al. ${ }^{[7]}$. showed mean age $14.2 \pm 3.2$ yrs. This study showed the majority of cases were ulcerative colitis in comparison to Gut et al.,
${ }^{[8]}$. showed most cases were crohn disease. This study showed mean body mass index (BMI) \pm SD was $18.3 \pm 2.4$ in comparison to Peradzy_nska et al. $(2012)^{[7]}$. Found mean BMI \pm SD was $19.5 \pm 2.2$. This study showed mean duration of disease (years) was 2.6 \pm 3.3 while Yilmaz et al ${ }^{[9]}$. showed Mean duration of disease (years) $3 \pm 0.5$.

This study showed that frequency of relapse classified as no relapse (40\%), mild (35\%), moderate $(20 \%)$ and sever (5\%). In comparison to Goyal A et al., ${ }^{[5]}$. Showed that no relapse $(58.6 \%)$, mild $(15.8 \%)$, moderate $(23.7 \%)$, severe $(60.5 \%)$, while Gut et al ${ }^{[8]}$ reported that no relapse $(55.6 \%)$, moderate $(33.3 \%)$ and severe $(11.1 \%)$. 
This study showed that medication used in treatment of IBD were Sulphasalazine (50\%), Sulphasalazine and azathioprine (25\%), Sulphasalazine and steroid (15\%), Steroid and infliximab (5\%) and Steroid, azathioprine, infliximab and colectomy (5\%) In comparison to Goyal A et al., ${ }^{[5]}$. Showed that ASA (89.7\%), Steroids (44.8\%), Azathioprine (18.4\%), Methotrexate $(2.3 \%)$ and Sulfasalazine $(10.3 \%)$. Our study showed that the most common Clinical findings were Abdominal pain and bloody diarrhea (25\%), Abdominal pain and weight loss (20\%). Abdominal pain and growth failure (10\%), Abdominal pain, bloody diarrhea and weight $\operatorname{loss}(10 \%)$ and Abdominal pain and bleeding per rectum(5\%) similar to Bequet E. et al., [10]. Showed that clinical presentation Abdominal pain, rectal bleeding, diarrhea, anemia and growth failure. This study showed that the most common Extra intestinal manifestations were Weight loss and pallor (20\%), Weight loss (15\%), Weight loss and clubbing (10\%), Oral ulcers and weight loss $(10 \%)$ and Uveitis, weight loss and pallor while Ji XQ et al., [1]. Extra intestinal manifestations were pyoderma gangrenosum and erythema nodosum), ocular (anterior uveitis and episcleritis), hepatic (pericholangitis and fatty liver), and articular (peripheral and axial arthropathies) diseases. Mouth ulcers and venous thrombosis also occur.

This study showed that mean level of hemoglobin $9.9 \pm 0.98$ in comparison with Goyal A et al. ${ }^{[5]}$. showed mean level 11 (6.7-15.3). 21.8 $20.7 \quad$ (mg/L) Our study showed that mean level of C-reactive protein While Gut et al ${ }^{[8]}$ mean level $3.2(0.7-11.4)$ $(\mathrm{mg} / \mathrm{L})$. Our study showed that mean level of erythrocyte sedimentation rate $44.7 \pm 19.2$ $(\mathrm{mm} / \mathrm{hr})$ while Gut et al., ${ }^{[8]}$ mean level $23.1 \pm 0.52(12-38)(\mathrm{mm} / \mathrm{hr})$.

This study reported that most cases were normal chest radiography which normal chest $\mathrm{x}$ ray $(85 \%)$ and abnormal $(15 \%)$ similar to Yilmaz et al., ${ }^{[9]}$ showed that chest $\mathrm{x}$ ray was often normal in patients with respiratory symptoms and IBD. Our study showed that Colonoscopy biopsy findings were Crypt abscess (35\%), Crypt abscess and neutrophilic infiltrate(35\%), Neutrophilic infiltrate (10\%), Granuloma and neutrophilic infiltrate $(10 \%)$ and Granuloma and crypt abscess (5\%) similar to Bousvaros A., et al. ${ }^{[11]}$ showed that granuloma, crypt abscess, neutrophilic infiltrate.

This study showed that Pulmonary function tests of the studied (IBD) patients were mean value of $\mathrm{FVC} \%$ was $78.7 \pm 5.7$ median (range) was 80 (66-87), mean value of FEV1\% was $78.2 \pm 3.1$ median (range) was 79 (70-82) median (range) was 1 (0.9-1.1) and mean value of FEV1/FVC ratio (Tiffeneau value). $95 \pm 0.05$ median (range) was $1(0.9-1.1)$ in comparison with Goyal A et al ., ${ }^{[5]}$ showed that median (range) of was FVC\% 87 (49145) median (range) was of FEV1 89 (51171) and median (range) of FEV1/FVC (Tiffeneau value) was 86 (63-120) and Herrlinger et al., ${ }^{[12]}$ which showed mean value of FEV1 $(81.4 \pm 3.3 \%)$, mean value of FVC (84.4 - 2.9\%) and mean value of FEV1/FVC (Tiffeneau value) (97.2 $\pm 2.4 \%$ ).

This study found that percentage of cases with abnormal pulmonary function (restrictive pattern) (30\%) and (obstructive pattern) $(10 \%)$ agree with, Sethy et al. ${ }^{[13]}$ reported most abnormal pulmonary function (restrictive pattern) 16\% of UC patients and disagree Yilmaz et al. ${ }^{\left[{ }^{[9}\right.}$ found that (7.69\%) patients had obstructive dysfunction, (5.12\%) had restrictive dysfunction, and (12.8\%) had abnormal diffusion, disagree with Godet et al., [14] Also found PFT abnormalities, obstructive pattern, abnormal DLCO, and restrictive pattern in $53 \%, 22.7 \%, 28.8 \%$, and $1.5 \%$ of patients with UC respectively.

This study showed that Statistically significantly moderate negative correlations existed between body mass index, frequency of attack of relapse and $\mathrm{FVC} \%$ in contrast with Goyal A et al., ${ }^{[5]}$ showed that BMI was not significantly different in patients with normal and abnormal PFT. While Herrlinger et al. ${ }^{[12]}$ found weak correlation between inspiratory vital capacity $(\mathrm{r}=0.25, \mathrm{P}<0.05)$ and BMI but not for FEV1.

This study showed that FVC\% was statistically significantly different among IBD patients grouped according colonoscopy biopsy findings $(P=.014)$.in comparison with 
Goyal A et al., ${ }^{[5]}$ showed that PFT values were abnormal in (12.5\%), (35.7), and $(28.6 \%)$ patients with proctitis, left-sided colitis, and pan colitis, respectively.

This study showed that statistically significantly moderate negative correlations existed between body mass index, frequency of attack of relapse and FEV1\% ( $P=.036$ and $P=.007$, respectively). Goyal $\mathbf{A}$ et al ., ${ }^{[5]}$ showed that BMI was not significantly different in patients with normal and abnormal PFT. Herrlinger et al. ${ }^{[12]}$ found no correlation between FEV1\% and BMI, Yilmaz et al., ${ }^{[9]}$ stated that there was no correlation between BMI and pulmonary function tests.

This study found that no statistically significant differences between Colonoscopy biopsy finding and PFT of the studied (IBD) patients IN Contrast with Yilmaz et al., [9] found association of increased respiratory symptom score with high endoscopic activity index in UC patients, but there was no correlation between respiratory symptoms and clinical activity of bowel disease. This study found that No significant relationship was found between duration of IBD and pulmonary function test results agree with Yilmaz et al., ${ }^{[9]}$ reported no relationship between duration of disease and PFT results.

Yilmaz et al. ${ }^{[9]}$ found that both the colonic and respiratory epithelia share embryonic origin from the primitive foregut. The inflammatory lesions seen beneath the bronchial epithelium are similar to those observed beneath the colonic epithelium in IBD. This means that there is inflammation that can be detected early by HRCT and pulmonary function tests. Although most patients have subclinical disease, the pulmonologist must be aware of the multiple potential pulmonary manifestations that can occur in a patient with IBD.

In the study by Louis et al., ${ }^{[15]}$ patients with IBD, free of pulmonary symptoms, which similar to our study absence of pulmonary symptoms in patients with IBD which showed abnormal pulmonary function tests .

Goyal A et al., ${ }^{[5]}$ found that Nutritional status (BMI, serum albumin, and $\mathrm{Hb}$ ) was not significantly different in patients with normal and abnormal PFT agree with our study no significant relation between hemoglobin, serum albumin and PFT In our study found that $(40 \%)$ of our cases reported abnormal PFT most of them were restrictive pattern while Mohamed-Hussein et al., ${ }^{[16]}$ fifteen out of 26 patients with UC had an important impairment in PFTs, Herrlinger et al., ${ }^{[12]}$ the impairment in PFTs was more pronounced in IBD patients with active disease than in those with inactive disease, Sethy et al., ${ }^{[13]}$ found deranged PFT in $17 \%$ patients with UC.

There was no relationship between treatment of UC with different drugs and abnormal PFT in our study which agree with Goyal A et al .${ }^{[5]}$ found no relationship between different drugs for UC and PFT.

In This study found that FVC\%, FEV1\% and FEV1/FVC ratio significantly decreased during relapse compared to their values before relapse $(P<.05)$ which agree with Mohamed-Hussein et al., ${ }^{[16]}$ found that FEV1 and FVC significantly decreased in patients with active disease as compared to those with an inactive disease and Herrlinger et al., ${ }^{[12]}$ reported that decrease PFT during relapse compared to those during remission

\section{CONCLUSION}

PFT abnormalities detected in patients with inflammatory Bowel diseases, Most of PFT abnormalities in This study were restrictive, Activity of IBD disease affect PFT which a non invasive diagnostic procedure in determining the activation of IBD.

The present study has some limitations including small number of patients and inability to perform the pulmonary function test for some children during excacerbations It Is recommended that PFT should be done for all cases of IBD to detect sub clinical abnormalities to confirm our result, PFT should be done for large scale of population because a large proportion of symptom free patients have abnormal findings on PFT, Advanced tests for pulmonary function should be done such as Gas dilution techniques: Helium dilution method and Nitrogen washed method, Body plethysmography, and Peak flowmetry. and Intermittent oscillation (IOS) for cases of IBD to detect another abnormalities. 
Conflict of interest: Nothing to declare

Financial disclosure: Nothing to declare REFERENCES

1. Ji XQ, Wang LX, Lu DG. Pulmonary manifestations of inflammatory bowel disease. World J Gastroenterol. 2014; 20: 1350113511.

2. Oliva-Hemker M, Hutfless S, Al Kazzi ES, Mack D, LeLeikoet N, Griffiths, et al. Clinical Presentation and Five-Year Therapeutic Management of Very Early-Onset Inflammatory Bowel Disease in a Large North American Cohort. J Pediatr 2015; 167:527.

3. Ott C, Schölmerich J. Extraintestinal manifestations and complication inIBD. Nat Rev Gastroenterol Hepatol. 2013; 10:585-595.

4. Casey MB, Tazelaar HD, Myers JL, Hunninghake GW, Kakar S, Kalra SX, et al. Noninfectious lung pathology in patients ithrohn's disease. Am J Surg Pathol. 2003; 27:213-219.

5. Goyal A, Ghoshal UC, Nath A, Jindal S, Mohindra S . Pulmonar function in patients with ulcerative colitis and its relationship with disease severity journal of gastroenterology and hepatology. 2017.

6. Larsen $\mathrm{S}$, Bendtzen $\mathrm{K}$, Nielsen $\mathrm{OH}$. Extraintestinal manifestations of inflammatory bowel disease: epidemiology, diagnosis, and management. Ann Med. 2010; 42: 97-114.

7. Peradzynska J, Krenke K, Lange J, Banaszkiewicz A, Lazowska-Przeorek I, Radzikowski A, et al.: Low prevalence of respiratory involvement in children with inflammatory bowel disease. Respir Med 2012; 106: 1048-1054.

8. Gut g, Amir Ben-Tov, Avishai Lahad, Ruth Soferman, Shlomi Cohen, Riva Taumana, et al. (2016): Pulmonary functions in children with inflammatory bowel disease. Eur $\mathrm{J}$ Gastroenterol Hepatol 28:708-713.

9. Yilmaz A, Yilmaz Demirci N, Hoşgün D, Uner E, Erdoğan Y, Gökçek A, et al. Pulmonary involvement in inflammatory bowel disease. World J Gastroenterol. 2010; 16(39): 4952-4957.

10. Bequet E, Sarter H, Fumery M, Vasseur F, Armengol-Debeir L, Pariente B, et al: Incidence and phenotype at diagnosis of veryearly-onset compared with later-onset paediatric inflammatory bowel disease: a population-based study [1988-2011]. J Crohns Colitis 2016; 11: pp. 519-526.

11. Bousvaros A, Antonioli D.A, Colletti RB, Dubinsky MC, Glickman JN, Gold BD, Griffiths AM, et al: Differentiating ulcerative colitis from Crohn disease in children and young adults: report of a working group of the North American Society for Pediatric Gastroenterology, Hepatology, and Nutrition and the Crohn's and Colitis Foundation of America. J Pediatr Gastroenterol Nutr. 2007; 44: pp. 653-674.

12. Herrlinger KR, Noftz MK, Dalhoff $K$, Ludwig D, Stange EF ,Fellermann $K$. Alterations in pulmonary function in inflammatory bowel disease are frequent and persist during remission. Am.J. Gastroenterol. 2002; 97: 377-381.

13. Sethy PK, Dutta U, Aggrawal AN, Das R, Gulati M, Sinha SK, Singh K. et al. Pulmonary and hematological alteration in idiopathic ulcerative colitis. Indian J.Gastroenterol. 2003; 22: 176-179.

15. Godet PG, Cowie R, Woodman RC, Sutherland LR. Pulmonary function abnormalities in patients with ulcerative colitis. Am.J.Gastroenterol. 1997; 92: 11541156.

16. Louis E, Louis $R$, Drion $V$, Bonnet $V$, Lamproye A, Radermecker $M$, et al. Increased frequency of bronchialhyperresponsiveness in patients with inflammatory bowel disease. Allergy 1995; 50: 729-733.

17. Mohamed-Hussein AA, Mohamed NA, Ibrahim ME. Changes in pulmonary function in patients with ulcerative colitis. Respir. Med. 2007; 101: 977-982.

\section{Cite This Article}

Abd-Elhamid, H., Hussien, H., Elsaadany, H. Pulmonary Function Tests in children suffering from Inflammatory Bowel Diseases in Zagazig University Hospital. Zagazig University Medical Journal, 2021; (3847): -. doi: 10.21608/zumj.2019.18291.1591 